\title{
About (relatively) common operations in digital architectures
}

\section{SIGRADI2018 TECHNOPOLITICAS \\ xxii congresso da sociedade iberoamericana de gráfica digital 22th conference of the iberoamerican society of digital graphics 07|08|09|novembro|2018 iau usp | são carlos | sp br}

\author{
Fábio Lima \\ Universidade Federal de Goiás - FAV/UFG | Brazil | arqfabiolima@gmail.com
}

\begin{abstract}
Many different types of algorithms have been associated to gain complex shapes. They give rise to a large set of unusual forms, through calculations based on computational geometries, self-organizing systems, rule-based systems, and optimization, often still assembled in morphogenesis principles. Many of these discoveries mimic physical, chemical, and even behavioral principles at the edge of this code-translated knowledge. Thus, any new form, the result of this exploratory perspective, can mean some progress. If the understanding of specific algorithmic characteristics has validity (for precise programming), generic concepts are also important for simplifying procedures and presenting general concepts of the result.
\end{abstract}

Keywords: Digital architecture; Computational geometry; Visual expression; Syntax generalities.

\section{INTRODUÇÃO}

As formas espaciais produzidas com 0 auxílio do computador se apresentaram desafiadoras desde os primórdios da computação gráfica, na conversão das expressões lógicas e abstratas para objetos visuais. No decorrer dos anos diversas características foram aprimoradas, intensificando processos de criação e raciocínio espacial, com recursos altamente sofisticados de projetação. Muitos arquitetos passaram a se utilizar de complexos algoritmos capazes de conduzir a formas altamente intricadas, nos limites das possibilidades construtivas e para além das visualidades do nosso âmbito comum.

As unidades geométricas básicas passam a ser articuladas de outras maneiras e não se pode reconhecer tacitamente a que categorias pertencem os procedimentos algoritmos apenas pela aparência final do modelo. Se no passado qualquer operação booleana era rapidamente compreendida, esse mesmo raciocínio dedutivo não é mais possível na maioria das arquiteturas digitais. Procedimentos baseados em contornos, ou de criação de sólidos de varredura (extrusão e revolução) passam a ocorrer em menor frequência, não sendo os principais responsáveis pela coordenação da composição. Muitos resultados se apoiam em geometrias computacionais (Triangulação de Delaunay, Diagrama de Voronoi, $A^{*}$ ), sistemas baseados em regras (Busca Estocástica, LSystems, Fractais), sistemas de auto-organização (Autômatos Celulares, Inteligência Coletiva) e também otimização (Algoritmos Genéticos). Se não bastasse, muitos desses procedimentos têm sido utilizados de forma associada, conduzindo a resultados muito excêntricos.

Muitas propriedades já conhecidas no passado também são rearticuladas, ganhando novas performances, já que a máquina permite associações e encadeamentos somente viáveis nesse âmbito digital. O limite da forma não se estabelece inicialmente numa definição geométrica prévia e visível. Pelo menos a princípio, já que muitas delas surgem numa conotação matemática abstrata. Surgem como equações, sistemas de regras, conjuntos com instruções e limites das variáveis em aberto: cálculos abrangendo muitos elementos simultâneos.

Por outro lado, mesmo havendo essas especificidades, há uma enorme vantagem no uso dos computadores porque eles permitem soluções muito similares por diferentes percursos. Pode haver grande proximidade nos resultados, pois as linguagens formais são configuradas em analogias ao raciocínio humano. Modelos relativamente similares podem ser obtidos por diferentes procedimentos computacionais, e as especificidades das linguagens formais nas quais foram concebidos são importantes. Se a compreensão de especificidades algorítmicas possui importância (visando caminhos claros de programação entre especialistas), os conceitos genéricos também se mostram relevantes, quando simplificam procedimentos e denotam os conceitos gerais que orientaram o resultado. Assim, por questões didáticas, várias dessas operações podem ser listadas pela ordem geral a que pertencem o modelo. Ao identificar características gerais desses casos, elas podem servir como instrumentos arrazoados de crítica, como recursos mais simplificados de avaliação, escopos para aprendizado, auxiliando assim outras referências e aplicações.

O espaço proporcionado pelos computadores permite que diferentes indivíduos possam se expressar e assim ampliar os processos de criação. Além disso, as máquinas possibilitam convergências digitais em redes, onde os processos comunicacionais têm se tornado cada vez mais complexos, relacionando diversos indivíduos, atores sociais, instituições e mídias. Nas sociedades pósindustriais, as instituições, os processos de tomadas de 
decisões, os hábitos de consumo, os modos de ver e perceber as coisas são transformados pela existência dessas redes e também das mídias. Esses aspectos influenciam constantemente o contexto social, os modelos comportamentais, o sentido dado à realidade (Barnett, 1997).

\section{METODOLOGIA}

Dentro dessa perspectiva de contínua transformação propiciada pela contaminação das mídias surgem exemplos muito diversos. Os exemplos a serem abordados aqui foram inicialmente apresentados em reportagens específicas de websites de arquitetura (AD Architectural Design, Arch Daily, eVolo, Dezeen, Arch2O, Designboom, Uncube Magazine, Archi Central, Architecture News Plus, Floornature, My Modern Met, Inhabitat). Essas revistas frequentemente enfatizam trabalhos ligados às novas tecnologias, ressaltando progressos nas soluções espaciais.

O número pequeno de casos constitui uma amostra relativa dentro de um universo muito mais amplo. Essa seleção deu-se pela evidência do resultado final como um tipo de sintaxe específica, onde algoritmos associados conduziram a uma composição arquitetônica menos profusa. A partir do princípio da unidade, observou-se a extensão do objeto ordenado em um todo, resultando num conjunto mais uniforme. No universo das formas digitais muitos casos não podem ser enquadrados em taxonomias comuns, onde topologias fluidas são associadas a elementos muito díspares, formas distorcidas, que sofreram algum tipo de colapso, compondo geometrias bastante irregulares. Desse modo, nos casos elucidados prevalece uma ordem que contribui para a síntese visual, que é, em outras palavras, sua simplificação.

Evidentemente, a partir da identificação dessas sintaxes, capazes de representar diferentes forças na gênese tectônica, com especificidades nas formações espaciais, pode-se posteriormente buscar uma pormenorização das suas características que permitiram torna-las arquiteturas singulares (seus procedimentos técnicos operacionais).

As discussões foram amparadas por Kolarevic (2000), Oxman (2005), Picon (2003), Terzidis (2006), Piazzalunga (2005) e Lima (2015). Além disso, Lévy (1999), Santaella (2012), Couchot (2003), Moles (1990), Castells, (2012), Machado (2000) e Flusser (2007) proporcionam também aberturas a debates multidisciplinares. Tanto as revistas digitais quanto esses autores contribuem indiscutivelmente para questões atuais, problematizando determinadas soluções e criando condições de perceber como uma parte da produção contemporânea se utiliza da máquina na contribuição singular de propostas arquitetônicas.

\section{RESULTADOS}

Vários fundamentos topológicos, generativos, paramétricos foram testados por arquitetos a várias décadas no intuito de observar e se apropriar dessas características. Como um traço da contemporaneidade, esse passado acumulado de experiências soma-se a técnicas recentemente desenvolvidas. Nas arquiteturas digitais as formas geométricas passaram a ser obtidas por simulações físicas, fluxos de dados, conversão de valores, transformações visuais, cujas bases não são realizadas por uma mera contraposição a uma corrente arquitetônica específica. A arquitetura digital não se fundamenta numa oposição específica, mas nas inúmeras aberturas dadas a casos passíveis de exploração por intermédio da máquina (Piazzalunga, 2005).

O algoritmo como espécie de versão racionalizada do pensamento humano contém tanto margens para objetividade e precisão, como também a imprecisão, a ambiguidade e a ambivalência. Apesar de diversas vantagens, muitos problemas não podem ser descritos sob a forma de algoritmos. Muitas vezes há o tratamento e a exploração de processos indeterminados, vagos, pouco claros, e muitas vezes mal definidos; por causa de sua natureza exploratória, a computação visa emular ou estender o intelecto humano. Trata-se de racionalização, dedução, indução, extrapolação, exploração e estimativa. Em suas múltiplas implicações, envolve a resolução de problemas, estruturas mentais, cognição, simulação e inteligência baseada em regras (Terzidis, 2006).

O agrupamento dos algoritmos muitas vezes segue princípios de morfogênese, descrições matemáticas baseadas em estruturas da natureza: reprodução aproximada de sistemas naturais acomodados nos limites desse conhecimento traduzido em código (Kolarevic, 2000). Para soluções da forma consideram-se fatores endógenos e exógenos: envolve a compreensão de muitos aspectos físicos e químicos interatuantes, tanto do interior desse corpo quanto da exposição ao ambiente externo (Couchot, 2003).

Desse modo, os processos digitais se enveredam por horizontes extremamente ambíguos e boa parte das vezes não são mais enquadrados sob uma única perspectiva ou lógica de formação. No ambiente digital os recursos são componíveis em camadas, se apropriam de conceitos e técnicas, hibridizam operações, de tal modo a tornarem-se indecomponíveis. Há uma fusão tão densa dos seus conceitos que a fragmentação das partes (análise, decomposição, exame de particularidades) raramente corresponde à virtude do objeto como um todo.

Além disso, também os modelos são construídos de maneira sistemática, por junção dos elementos, de acordo com um certo número de regras estruturais (Moles, 1990). Os modelos são criados pelas suas condições estruturais de linguagem formal, podendo ser manipulados por expressões e funções de mistura. Nessa "matéria digital" são permitidas operações nos mais variados escopos, transformações muitas vezes impossíveis nos estados do mundo físico. Elas permitem criar, editar, compor, liquefazer, metamorfosear, etc., (Machado, 2000) numa mudança que tem ação de resposta calculada em tempo real.

Nessas novas geometrias, não basta apenas dizer não euclidianas, mas reconhecer suas características gerais. Nas diversas operações realizadas com a máquina, muitas delas incorrem estágios processuais e simulam propriedades físicas. Por exemplo, uma geometria qualquer a ser definida pelos parâmetros da água pode adequar dados impossíveis no mundo físico, em camadas capazes de ajustar os índices de viscosidade, de transparência, de solidificação, etc., ocorrendo de modo simultâneo. 
Muitas possibilidades que hoje são consideradas comuns nos softwares comerciais como um tipo de efeito, na verdade ocorreram porque muitos cientistas desejavam reproduzir com grande fidedignidade algumas condições específicas existentes no meio físico: propriedades da água, fogo, névoa, crescimento das plantas, formação das nuvens, etc. E somente se tornaram representáveis porque foram encontradas operações matemáticas capazes de descrever de forma aproximada a complexidade geométrica desses casos. A partir dessas experiências é que se fundamentaram como algoritmos. Esse aspecto é também determinante no uso do computador: uma vez encontrada certa propriedade, ela é tratada como um conjunto de procedimentos (relações que amparam construções geométricas), sendo posteriormente empregadas em contingências específicas.

Ao atribuir valores diferentes para os parâmetros, objetos ou configurações diferentes podem ser criados. As equações podem ser usadas para descrever as relações entre objetos, definindo assim uma geometria associativa, geometria componente mutuamente ligada (Kolarevic, 2000). Assim, há interdependência uns dos outros, onde a probabilidade de mudança depende do conjunto dos que os precederam numa dada sequência. Os elementos sucessivos constituem um processo em cadeia (Moles, 1990).

Além disso, muito antes de serem geometrias propriamente ditas, são computadas algebricamente como sistemas de regras e restrições. Antes de conterem propriedades geométricas claramente definidas, visíveis e descritíveis, os fatores iniciais envolvidos não podiam ser apreendidos numa resposta formal evidente. Por exemplo, os sistemas podem criar vetores de ventos, capazes de afetar um determinado modelo, contando com direções alternantes e intensidades diversas. Não se pode prever exatamente como afetarão o modelo e como essa resultante pode beneficiar outras tomadas de decisões. A maioria das operações iniciais pode ser completamente traçada por expressões matemáticas, mas ao final, sua complexidade poderá ser tão descritível quanto a geometria de uma névoa.

A ideia de sintaxe prevalece ainda hoje como a apropriação sobre um conjunto existente de elementos a serem compostos. Por muito anos a criação arquitetônica tratou de desenvolver uma proposta em conformidade a um vocabulário existente. Esse conjunto deveria aludir às geometrias básicas, a formação de sólidos primários compostos de tal modo que, cumprindo os requisitos iniciais de um programa arquitetônico, deveriam ser associados e igualmente promoverem algum caráter de beleza. O que muda na atualidade são as suas associações, os princípios de reunião.

Ainda que vários desses casos possam ser considerados bastante ilustrativos, apresentam visualidades que ocorrem também em outros segmentos das artes digitais. Nesse contexto digital de frequentes trocas e contaminações as extensões do que essas artes podem proporcionar tornam amplas e difusas as resultantes arquitetônicas (Lima, 2015). Uma operação de "furar", por exemplo, é um recurso de trespasse do edifício capaz de criar um impacto na sua forma pelo resultado orgânico surpreendente. Assim, algumas dessas tomadas de decisões podem aparecer com uma função subversiva, ao romper operações habituais. Isso não significa que sejam as únicas responsáveis por esse processo de inovação, mas seu caráter tipicamente transgressor permite inovar muitas combinações.

A Tabela 1 na página seguinte é constituída por 5 colunas, apresentando operações elementares, os cânones (imagens arquetípicas dessas operações), um modelo computacional correspondente e, por fim, um exemplo arquitetônico (dentre vários existentes). Os edifícios selecionados representam uma diversidade muito grande de abordagens. É impossível esgotar todas as categorias a que pertencem os resultados finais dos modelos digitais. Enquanto umas se apoiam em dar novas feições a procedimentos do passado (promovendo um revival nostálgico de referências), outras se especializam e esquadrinham operações conhecidas. Assim, seccionar, ondular, torcer, furar e etc. são minuciosamente investigadas, pesquisadas na intenção de se obter maior singularidade, maior ênfase em relação a preexistências do passado. Essas sintaxes atingem um grau de enorme especialização, sendo esmiuçadas na intenção de criarem um forte enlevo na forma arquitetônica.

Há modelos digitais cujos processos são baseados nas chamadas polisuperfícies isomórficas, as entidades conhecidas como blobs ou metaballs (Blain, 2011). São modelos de aparência globular, utilizados para simular a fluidez dos líquidos e também elementos viscosos. Já a metamorfose de objetos inclui diversas técnicas, da mais elementar, a animação por quadros-chaves, às deformações do modelo por envelope, onde um objeto é usado como receptáculo para outro. Há situações ainda onde objetos seguem uma determinada trajetória e se alteram nesse caminho, em função da velocidade imprimida e também das curvaturas capazes de o deformar naquela direção, possibilitando o controle de distorções graduais. Em todas as circunstâncias ocorre uma mudança da forma por interpolação, que pode ser registrada como keyframe ou keyshape para ser adequada a propósitos arquitetônicos. $\mathrm{Na}$ animação define-se a copresença da força do movimento na concepção do objeto arquitetônico, produzindo inflexões na forma. O movimento implica em ação, e a animação implica em alteração da forma, por vários tipos de sistemas cinéticos: wave, wind, twist, etc., cinemática direta e inversa ou emissão de partículas tais como fire, smoke, fog, etc. (Kolarevic, 2000).

Já padrões organizados em células costumam seguir o processo de subdivisão espacial concebido por George F. Voronoy. A geometria surgida por esse diagrama constituise num fenômeno de organização que mimetiza de modo parcial diversas soluções existentes na natureza. Nesse tipo de divisão espacial, diferentes configurações de pontos resultam em muitos tipos de células, capazes de se alterarem à medida que são acrescentados ou removidos.
3 


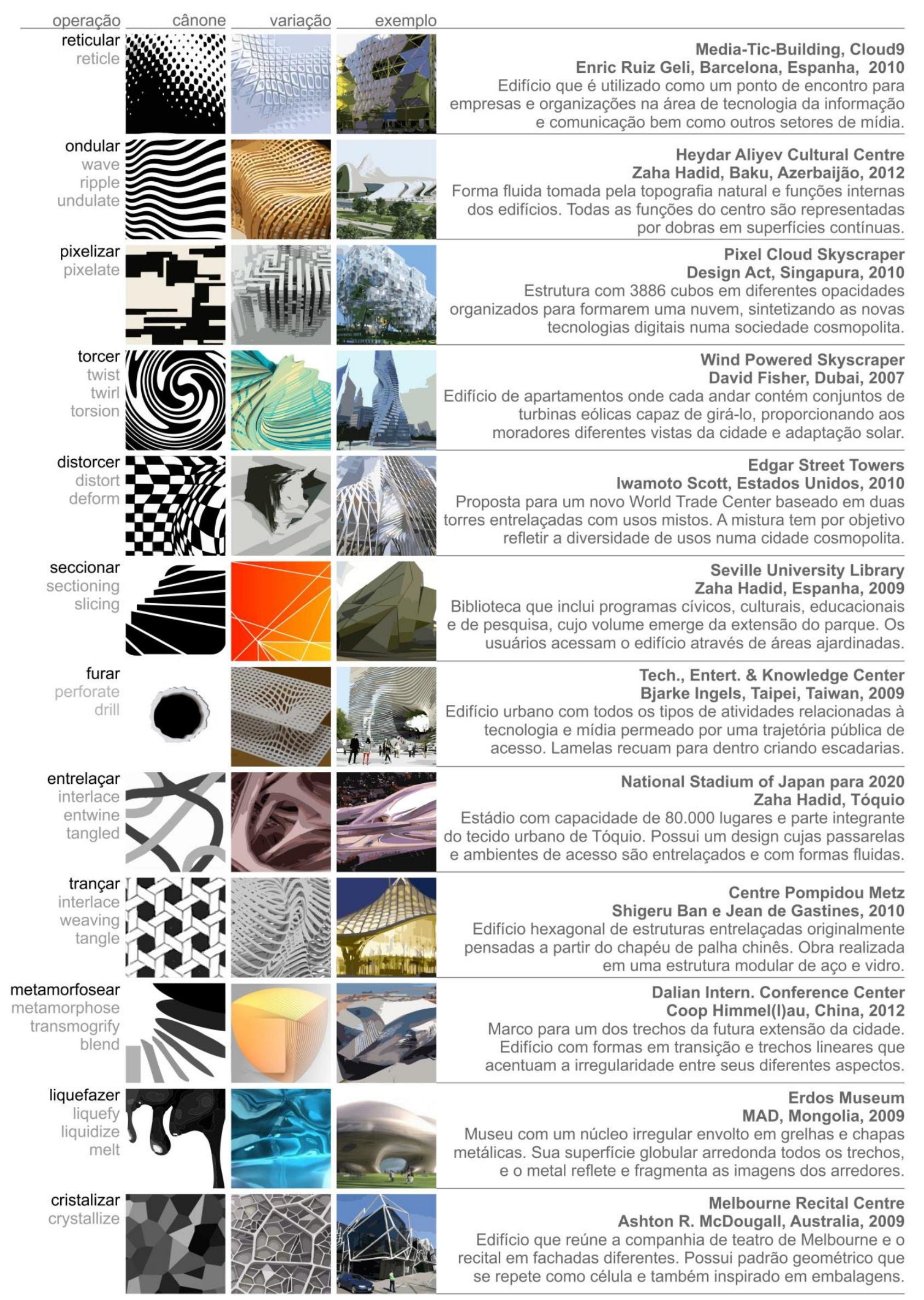


Desse modo, o método computacional específico provê e também modifica, no limite tangível das suas características, o que cada técnica em particular possui em termos de atributos, às quais observadas em menor escala podem parecer simples, mas resultam em modelos completamente diferentes uns dos outros. Assim, pode-se afirmar que as técnicas digitais avançadas não estão simplesmente mudando as formas de representação, mas igualmente forjando novas bases para um pensamento projetual (Oxman, 2005), onde a liberdade poética pode ser igualmente combinada com recursos tecnológicos altamente úteis.

Esses modelos digitais colocam em contenda problemas de uma identidade forjada segundo limites visuais expressos matematicamente: a sua potência em existir, sob qualquer aspecto, está vinculada ao espaço digital, cuja característica é a imaterialidade, a ausência de gravidade e a artificialização ou simulação de um lugar (Machado, 2000). Entretanto, não são simples elucubrações sem propósito, seus autores intentam aspectos muito difíceis de execução, de validade tectônica. $E$ assim os exemplos surgem promovendo novas questões da forma e da utilidade que não apenas referenciam o computador, mas exacerbam um modelo tecnológico irregular, em práticas incomuns, alternativas e dissidentes, reforçando um profundo empenho por novas experiências.

\section{DISCUSSÕES}

Por centenas de anos célebres matemáticos obtiveram resultados capazes de ir para além dos seus âmbitos conhecidos, mas não seguiam adiante porque consideravam seus ganhos inadequados. O fato é que novas geometrias não eram pensadas de forma metódica porque também suas configurações irregulares simplesmente pareciam não servir para nada. Tanto a demonstração matemática quanto a modelização gráfica proporcionavam resultados amorfos, nas quais contradiziam uma base lógica fundada na exposição regular e regrada por funções acessíveis. Os modelos regulares sempre se constituíram frutos de um processo de codificação da experiência, quando asseveram possibilidades de uso, tornando-se também um exemplo de informação válida (Flusser, 2007).

O surgimento das novas geometrias tornou evidente o quanto uma visão de mundo estava delimitada pelos conceitos euclidianos. Ela restringia não apenas um tipo de raciocínio lógico, mas principalmente uma forma de pensar incapaz de romper diversos tipos de juízos, numa mecânica simplificadora da realidade. Às vezes criando fascínio e outras vezes repulsa, a libertação do pensamento matemático limitado a modelos regulares fez perder muitas condições estáveis do que poderia ser descrito formalmente. As novas geometrias exigiram, de fato, o rompimento com paradigmas, do que parecia ser um conhecimento seguro da realidade, além da quebra de preconceitos para que se pudesse fazer avançar o conhecimento. De qualquer modo, todos esses aspectos identificam estruturas de pensamento na qual o número é reconhecido como um produto exclusivo do nosso espírito, enquanto o espaço é uma realidade para além desse espírito, cujas leis não podem ser prescritas completamente (Flusser, 2007).
Nessa situação anterior, as geometrias básicas preservavam seus fundamentos primários e resguardam a pureza da forma. Os modelos mais simples estão diretamente relacionados à facilidade da realização construtiva. Além disso, o arquiteto pode rapidamente executar desenhos e maquetes para pensar com mais critério suas propostas. Assim, o processo parte dos elementos geradores da forma, os quais correspondem os seus dimensionamentos, de tal maneira que a expressão plástica possui grande afinidade à natureza técnica das tecnologias disponíveis.

Vários problemas de construção geométrica são superados, tanto no seu aspecto visual (do ponto de vista exequível e prático), quanto das suas relações algébricas (muitas vezes considerado teórico, por estar associado ao algoritmo em formulação). Nas abordagens da sintaxe, ainda que as unidades elementares do ponto, reta e plano sejam essenciais e reconhecidas nas propriedades descobertas no passado, podem ser reportadas noutras categorias racionais. Os softwares não apenas permitem explorar conjunturas espaciais, mas aprofundar nos processos possíveis de estruturação física, orientando subdivisões de unidades e criação de sistemas interligados.

Por outro lado, com o uso dos computadores, a partir das unidades geométricas elementares são lançadas diversas associações reconfigurando seus grupos e conduzindo também a objetos pouco plausíveis. Ao que tudo indica teoricamente confirmado nas teorias da sintaxe, é praticamente impossível esgotar o universo das formas espaciais. E desse modo, há sempre alguma nova possibilidade a ser desenvolvida.

As complexidades da criação artística e arquitetônica, na medida do possível, passaram se relacionar com conceitos e novos princípios desenvolvidos noutros campos, nas Ciências da Computação, Matemática, Biologia Evolutiva, Química Molecular, Psicologia Comportamental, Ciências Cognitivas e Cibernética, alcançando características transdisciplinares (Santaella, 2012).

Assim, esses novos modelos colocam em crise (entendida aqui como mudança, ruptura no desenvolvimento de processos e perturbação nas relações de continuidade) os diversos sistemas de representação (Plaza; Tavares, 1998). Também as várias linguagens fundadas pelas experiências representativas do âmbito da arte se referem a características representativas (e bastante variáveis nas suas percepções).

As categorias dos fenômenos perceptivos das formas visuais foram ostensivamente estudadas ao longo dos anos (Arnheim, 2002); (Dondis, 1997), como elementos objetivos da experiência, a serem utilizados em concepções específicas. Surgem como impulsos e podem ser abstraídos de casos variáveis, podem ser utilizados de modo muito consciente na obtenção de algum efeito. Os exemplos são alinhados e produzem um efeito, portanto a arte é utilizada como um signo visual de transferência, de significado (quando possível) e de impulso estético nem sempre claro ou qualificado.
5 


\section{CONCLUSÃO}

É importante destacar que a tecnologia não é neutra e ela não tem um fim em si mesma. Ela é um meio para a obtenção de outras coisas. A partir dessa consideração é possível adentrar ao controverso universo tecnopolítico, não tratando apenas do uso das ferramentas digitais, mas de um espaço de mediação fundamental no desenvolvimento das pessoas, ampliando seus níveis de informação e conhecimento, na possibilidade crítica de transformação da realidade (Castells, 2012).

A partir de experiências pessoais, investigações específicas por meio dos computadores e suas posteriores difusões em redes, estas passam a se tornar um bem comum, um conjunto de informações e experiências úteis à coletividade. Além disso, esse conhecimento criado e partilhado não é estanque, por haver desdobramentos significativos desse saber. Por estar permanentemente aberto a contribuições, permite alavancar rumos muito prósperos do conhecimento. Nesse sentido, parece correto concordar que a experiência coletiva sobre uma determinada forma de operar sobre a realidade, especialmente nessa conjuntura contemporânea, compreende aspectos advindos das operações midiáticas e, particularmente, do conjunto dessas mídias, em especial a internet (Lévy, 1999).

Assim são formados novos sujeitos, novas subjetividades, novas aberturas às mais diversas questões, caracterizando um espaço político democrático. Todo e qualquer assunto mediatizado pode se constituir numa abordagem transversal, valorizando um contexto democrático do conhecimento. Numa visão particular da tecnopolítica, tudo pode mudar no sentido mais útil, como um bem comum a todos.

As tecnologias computacionais dinamizaram a produção da arquitetura e fomentaram possibilidades: desde a validade conceitual das propostas, passando pela efetividade de uso ou características de emprego, até chegar a certos casos onde ocorre sua impossibilidade de execução física, abrindo brechas para críticas negativas de críticos conservadores que veem nesses modelos apenas instrumentos para constructos ficcionais. Entrementes a muitas propostas, a grande maioria leva em consideração necessidades subjacentes do projeto, implicando em dados consistentes, em enunciados com coerências internas e soluções adequadas de raciocínio projetual como em qualquer outra circunstância requerida de projeto.

A arquitetura está sempre à mostra para um público genérico, e bastante influenciado pelo imaginário ofertado pelo cinema, televisão, internet, mídias impressas, design especializado, etc. numa adoção cada vez mais frequente das estratégias visuais oriundas desses meios. Além dessas contaminações, as sintaxes se tornam altamente especializadas pelos recursos digitais, escavando continuamente outras possibilidades.
Essas diferentes estratégias permitem observar que não apenas os procedimentos se alteraram, mas principalmente 0 interesse, a sensibilidade para os diversos tipos de fenômenos que nos cercam. Muitas predisposições foram perturbadas por conta das diversas visualidades em circulação. Elas afetam profundamente a sensibilidade para todas as coisas, o modo como se estabelece certas consonâncias e expectativas, que sejam capazes de suprir os desejos mais recônditos.

\section{REFERÊNCIAS}

Arnheim, R. (2002). Arte e percepção visual: uma psicologia da visão criadora. Trad. Ivonne Terezinha de Faria. São Paulo: Pioneira Thomson Learning.

Barnett, S. (1997). New media, old problems: new technology and the political process. European Journal of Communication, v.12, n.2.

Blain, J. M. (2011). The complete guide to blender graphics. Computer modeling \& animation. New York: CRC Press, Taylor \& Francis Group.

Castells, M. (2012). Redes de indignación y esperanza: los movimientos sociales en la era de internet. Madrid: Alianza.

Couchot. E. (2003). A tecnologia na arte: da fotografia à realidade virtual. Porto Alegre: Ed. da UFRGS.

Dondis, D. (1997). A Sintaxe da linguagem visual. Trad. Jefferson Luiz Camargo. São Paulo: Martins Fontes.

Flusser, V. (2007). O mundo codificado: por uma filosofia do design e da comunicação. Trad. Raquel Abi-Sâmara. São Paulo: Cosac Naify.

Kolarevic, B. (2000). Digital morphogenesis and computational architectures. In 4ํㅗ SIGRADI, Rio de Janeiro, 1-6.

Lévy, P. (1999). Cibercultura. Trad. Carlos Irineu da Costa. São Paulo: Ed. 34.

Lima, F. F. (2015). Espaços sem fronteiras: arte e arquitetura digital. Tese em arquitetura e urbanismo, Unb, Brasília. Disponível em http://repositorio.unb.br/handle/10482/19550.

Machado, A. (2000). Máquina e imaginário. São Paulo: Senac.

Moles. A. (1990). Arte e computador. Trad. Pedro Barbosa. Porto, Portugal: Edições Afrontamento.

Piazzalunga, R. (2005). A virtualização da arquitetura. Campinas, SP: Papirus.

Picon, A. (2003). Architecture, Science, Technology, and the Virtual Realm. In Picon. A. \& Ponte, A. (Eds.) Architecture and the sciences: exchanging metaphors, New York: Princeton Papers on Architecture.

Plaza, J. \& Tavares, M. (1998). Processos criativos com os meios eletrônicos: poéticas digitais. São Paulo: Hucitec.

Santaella, L. (2012). A relevância da arte-ciência na contemporaneidade. In Rocha, C.; Medeiros, M. B.; Venturelli, S. (Orgs.) Art. Arte e Tecnologia. Modus Operandi Universal. Brasília. Disponível em http://www.medialab.ufg.br/art/wpcontent/uploads/ 2012/10/Livroart.pdf.

Terzidis, K. (2006). Algorithmic Architecture, Oxford: Architectural Press/Elsevier. 